\title{
Incidence of and risk factors for chloroquine and hydroxychloroquine retinopathy in Thai rheumatologic patients
}

This article was published in the following Dove Press journal:

Clinical Ophthalmology

2 November 2016

Number of times this article has been viewed

\author{
Nuanpan Tangtavorn \\ Yosanan Yospaiboon \\ Tanapat Ratanapakorn \\ Suthasinee Sinawat \\ Thuss Sanguansak \\ Chavakij Bhoomibunchoo \\ Wipada Laovirojjanakul \\ KKU Eye Center, Department of \\ Ophthalmology, Faculty of Medicine, \\ Khon Kaen University, Khon Kaen, \\ Thailand
}

Objective: To study the incidences of and risk factors for chloroquine (CQ) and hydroxychloroquine (HCQ) retinopathy in Thai rheumatologic patients.

Methods: A retrospective cohort study of 234 rheumatologic patients receiving either CQ or HCQ was conducted. Patients were divided based on whether or not they developed retinopathy as retinopathy-positive or negative groups. Medical records giving details regarding age, gender, body weight, underlying diseases, daily doses, and cumulative doses of CQ or HCQ were reviewed. CQ and HCQ retinopathy were diagnosed by indirect ophthalmoscopy, Humphrey visual field test, and optical coherence tomography. The main outcome measures were incidences and risk factors of CQ and HCQ retinopathy.

Results: The CQ retinopathy was detected in 14 of 173 patients (8.09\%) who received CQ for 139-2,033 days, cumulative doses from 14.3 to $325.1 \mathrm{~g}$, and daily doses from 0.8 to $18.5 \mathrm{mg} / \mathrm{kg} / \mathrm{d}$. Their ages ranged from 27 to 65 years. When compared to the CQ retinopathy-negative group, only age, body weight, and cumulative dose showed statistically significant differences. The HCQ retinopathy-positive group was comprised of 2 of 61 patients $(3.28 \%)$ who received HCQ for $660-828$ days, cumulative doses from 80 to $130 \mathrm{~g}$, and daily dose from 1.9 to $4.4 \mathrm{mg} / \mathrm{kg} / \mathrm{d}$. Their ages were 36 and 39 years. Compared to the HCQ retinopathy-negative group, there were no statistically significant differences in studied risk factors.

Conclusion: Incidences of and risk factors for CQ and HCQ retinopathy were reported. Since most patients developed retinopathy earlier than 5 years, it is suggested that patients taking long-term CQ or HCQ should undergo ophthalmologic screening annually after the baseline examination.

Keywords: chloroquine, hydroxychloroquine, retinopathy, incidence, risk factors

\section{Introduction}

Chloroquine (CQ) and hydroxychloroquine (HCQ) are widely used to control effects of various rheumatologic diseases, for example, rheumatoid arthritis (RA), systemic lupus erythematosus (SLE), systemic sclerosis (SS), or other connective tissue diseases. They are found to inhibit CD4 T-cell stimulation while also promoting CD8 T-cell stimulation, and hence they are a popular choice for controlling the progression of autoimmune diseases without increasing the rate of opportunistic infections. ${ }^{1} \mathrm{HCQ}$ is more molecularly polar than CQ making it less lipophilic, leading to poorer diffusion through biological membranes and resulting in less toxicity. ${ }^{1}$ One of the most severe complications of these drugs is retinopathy, which leads to visual field defects and visual loss as a result of damaged photoreceptors. This damage is incurable and may progress even after the drugs are discontinued. ${ }^{2}$ An ophthalmologic screening
Correspondence: Yosanan Yospaiboon KKU Eye Center, Department of Ophthalmology, Faculty of Medicine, Khon Kaen University, 123 Mitraparb Highway, Khon Kaen 40002, Thailand Tel +66 43348383

Email yosanan@kku.ac.th $\mathrm{BY}$
hC for commercial use of this work, please see paragraphs 4.2 and 5 of our Terms (https://www.dovepress.com/terms.php). 
examination, therefore, has to be regularly performed to early detect and prevent this destructive morbidity. ${ }^{2}$

The American Academy of Ophthalmology (AAO) established guidelines for CQ and HCQ retinopathy screening examinations, which was revised in 2011 and 2016. ${ }^{3,4}$ Patients were classified as high risk when they have at least one of the following risk factors: an average daily dose exceeding $2.3 \mathrm{mg} / \mathrm{kg}$ real weight for CQ and $5 \mathrm{mg} / \mathrm{kg}$ real weight for $\mathrm{HCQ},{ }^{4}$ cumulative doses exceeding $460 \mathrm{~g}$ for CQ and 1,000 $\mathrm{g}$ for $\mathrm{HCQ},{ }^{3}$ a duration of treatment exceeding 5 years, being elderly, having concomitant renal disease, or using Tamoxifen. ${ }^{4}$ Routinely, one baseline examination within the first year and annual screening beginning 5 years after the first dose are recommended. ${ }^{3,4}$

Since most of studies reported are performed in Caucasian populations, ${ }^{5-8}$ application of the findings of these studies and recommendations may not be appropriate for Asian populations. For the Thai patients, there have been some studies on prevalence and risk factors of CQ retinopathy, but the results seemed to be paradoxical to the AAO recommendations, and the obvious risk factors are still not well defined. ${ }^{9-11}$ Hence, this study was intended to produce a more inclusive report on incidence of and risk factors for CQ and HCQ retinopathy in Thai rheumatologic patients.

\section{Subjects and methods}

This study was conducted in accordance with the tenets of the Declaration of Helsinki and was approved by the Khon Kaen University Ethics Committee for Human Research (HE571052). The Khon Kaen University Ethics Committee for Human Research waived the requirement for patient consent due to the retrospective nature of the study. A retrospective cohort study of rheumatologic patients at Srinagarind Hospital, Khon Kaen University, Thailand, was conducted. The patients, aged not less than 18 years old, started receiving either CQ or HCQ from 2004 to 2014 and regularly underwent eye screening examinations for CQ or HCQ retinopathy at the KKU Eye Center. Patients whose medical records were incomplete or those who had undeterminable records of the CQ or HCQ dosages were excluded. Also, patients who started the drugs before being referred to the hospital or were switched from CQ to HCQ or vice versa were excluded. Moreover, patients with retinal or macular diseases or optic neuropathy, which could possibly interfere with the visual field test, were excluded as well.

\section{Data collections}

The medical records of all the patients who fulfilled the criteria mentioned in the "Subjects and methods" section were reviewed and recorded in prepared case report forms. The record form for each patient was labeled with a new number to conceal the real identity of patients. The information collected were:

- Age: the age at the latest eye examination.

- Gender: male or female.

- Body weight: the real body weight at the latest follow-up at the rheumatologic clinics.

- Underlying disease: diabetes mellitus, dyslipidemia, hypertension, or other diseases.

- History of rheumatologic diseases.

- Duration of drug use:

- If the patients had no retinopathy and still continued the drug, it was counted from the day of the first dose to the day of the last eye examination.

- If the patients had no retinopathy and stopped the medication, it was counted from the day of the first dose to the day of the last dose.

- If the patients had retinopathy, it was counted from the day of the first dose to the day that retinopathy was diagnosed despite whether patients had stopped the medication or not.

- Cumulative dosage (g): For each patient, the dosage, the duration of each dosage, and dose changes throughout treatment were recorded. The summation of products of dosage and duration were recorded as the cumulative dosage.

- Average dosage per real body weight per day $(\mathrm{mg} / \mathrm{kg} / \mathrm{d})$ : Cumulative dose divided by real body weight and duration in days each patient received the medication.

- Presence of signs of CQ or HCQ retinopathy from the eye screening examinations.

\section{Determination of $\mathrm{CQ}$ and $\mathrm{HCQ}$ retinopathy}

According to AAO recommendations, retinal toxicity was defined in 2 levels: "possible" toxicity and "probable" toxicity. ${ }^{3}$ Possible toxicity indicates an early sign of toxicity. Patients who repeatedly demonstrated these conditions in both eyes for at least 2 consecutive tests were recommended to stop the medications until the cause, other than CQ or HCQ retinopathy, was identified. These conditions were:

- Parafoveal depigmentation of retinal pigment epithelium (RPE) as observed by indirect ophthalmoscopic examination after patients' pupils were fully dilated.

- Decreased parafoveal visual field sensitivities at the same area for at least 2 consecutive visits as tested by Humphrey visual fields (HVF) 10-2 using Humphrey Field 
Analyzer II (Zeiss Meditech Inc., Dublin, CA, USA). All the tests must show reliable test-fixation loss of less than $20 \%$ and have false-negative and false-positive response rates of less than 33\%.

- Loss of parafoveal inner segment-outer segment junction from spectral domain optical coherence tomography (OCT) using Spectralis (Heidelberg Engineering, Heidelberg, Germany).

- Increased autofluorescence at parafoveal area using Spectralis (Heidelberg Engineering).

For probable toxicity, the same findings as in possible toxicity were included, but those defects were shown in the bull's eye pattern and in both eyes.

The screening tests were routinely performed and interpreted by retinal specialists at the KKU Eye Center.

\section{Sample size calculation}

Estimated sample size was calculated with $95 \%$ confidence level, $5 \%$ absolute precision, and $13.5 \%$ estimated prevalence, resulting in a sample size of $171 .{ }^{9}$

\section{Statistical analysis}

As these data did not match that of normal distribution, continuous data were reported as the median with minimal and maximal values, and comparisons between data of each group were performed using Mann-Whitney tests. Categorical data were compared via Fisher exact tests. The risk factors were analyzed as hazard ratios using univariate Cox regression analysis. The incidence of retinopathy and the duration of the medication use were demonstrated with Kaplan-Meier survival analysis. The risk factors that had a value of $P<0.2$ were further analyzed with multivariate
Cox regression analysis. All statistics were performed using SPSS for Windows version 20.0 (IBM Corporation, Armonk, NY, USA). The statistical significance was defined at $P<0.05$.

\section{Results}

Two hundred and thirty-four patients were enrolled in the study according to the criteria established. There were 173 patients who received only CQ (CQ group) and 61 patients who received only HCQ (HCQ group). In the CQ group, there were 63 RA patients, 63 SLE patients, 23 SS patients, and 24 patients with other connective tissue diseases. In the HCQ group, there were 11 RA patients, 31 SLE patients, 4 SS patients, and 15 patients with other connective tissue diseases.

In the CQ positive group, retinopathy had developed in 14 of 173 patients, all of which were categorized "possible" toxicity as evidenced by indirect ophthalmoscopic examination, HVF test, and OCT findings. The specific details of these patients are shown in Table 1. The incidence of CQ retinopathy was $8.09 \%$ of the patients who used CQ over the 10 years considered. The risk factors are shown in Table 2 . It was noted that only age, real body weight, and cumulative dose showed statistical significance at $P<0.05$. Moreover, other coexisting diseases, thyroid disease, heart disease, and anemia, in both the retinopathy-positive and the retinopathy-negative groups were recorded. Also, hepatitis B virus infection, nasopharyngeal carcinoma, pulmonary tuberculosis, Parkinson's disease, and renal disease in the retinopathy-negative group were recorded. Unfortunately, the numbers of these diseases were too small to statistically compare the data.

Table I Specific details of the patients with CQ retinopathy

\begin{tabular}{|c|c|c|c|c|c|c|c|c|c|c|}
\hline Number & $\begin{array}{l}\text { Age } \\
\text { (years) }\end{array}$ & Gender & $\begin{array}{l}\text { Weight } \\
\text { (kg) }\end{array}$ & $\begin{array}{l}\text { Underlying } \\
\text { diseases }\end{array}$ & $\begin{array}{l}\text { Rheumatologic } \\
\text { diseases }\end{array}$ & $\begin{array}{l}\text { Duration } \\
\text { (days) }\end{array}$ & $\begin{array}{l}\text { Cumulative } \\
\text { dose }(\mathrm{g})\end{array}$ & $\begin{array}{l}\text { Cumulative } \\
\text { dose/kg (g/kg) }\end{array}$ & $\begin{array}{l}\text { Daily dose/d } \\
\text { (mg/d) }\end{array}$ & $\begin{array}{l}\text { Daily dose/kg/d } \\
(\mathrm{mg} / \mathrm{kg} / \mathrm{d})\end{array}$ \\
\hline I & 63 & $\mathrm{~F}$ & 48 & No & SS & 279 & 32 & 0.67 & 114.69 & 2.39 \\
\hline 2 & 49 & $M$ & 65 & No & RA & 140 & 35 & 0.54 & 250 & 3.85 \\
\hline 3 & 54 & $M$ & 54 & No & RA & 791 & 191 & 3.54 & 241.47 & 4.47 \\
\hline 4 & 27 & $\mathrm{~F}$ & 58 & No & RA & 897 & 201 & 3.47 & 224.08 & 3.86 \\
\hline 5 & 59 & $\mathrm{~F}$ & 55 & No & RA & 139 & 14 & 0.26 & 100.72 & 1.83 \\
\hline 6 & 50 & $\mathrm{~F}$ & 56 & Thyroid & SLE & $\mathrm{I}, 023$ & 263 & 4.69 & 257.09 & 4.59 \\
\hline 7 & 56 & $M$ & 59 & No & SLE & 194 & 41 & 0.69 & 211.34 & 3.58 \\
\hline 8 & 65 & $M$ & 60 & DM, HT & RA & 1,159 & 302 & 5.03 & 260.57 & 4.34 \\
\hline 9 & 45 & $\mathrm{~F}$ & 51 & No & SLE & 1,189 & 139 & 2.72 & $|16.9|$ & 2.29 \\
\hline 10 & 53 & $\mathrm{~F}$ & 98 & $\mathrm{DM}, \mathrm{DL}, \mathrm{CHF}$ & UCTD & 2,033 & 325 & 3.32 & 159.86 & 1.63 \\
\hline II & 45 & $\mathrm{~F}$ & 56 & No & SLE & $\mathrm{I}, \mathrm{I} 54$ & 64 & I.I4 & 55.46 & 0.99 \\
\hline 12 & 44 & $M$ & 60 & No & CPA & 269 & 63 & 1.05 & 234.2 & 3.90 \\
\hline 13 & 36 & $\mathrm{~F}$ & 73 & No & SLE & 300 & 75 & 1.03 & 250 & 3.42 \\
\hline 14 & 64 & $M$ & 68 & No & RA & 657 & 194 & 2.85 & 295.28 & 4.34 \\
\hline
\end{tabular}

Abbreviations: $\mathrm{CQ}$, chloroquine; F, female; M, male; RA, rheumatoid arthritis; SLE, systemic lupus erythematosus; SS, systemic scleroderma; CPA, chronic polyarthritis; UCTD, unspecified connective disease; DM, diabetes mellitus; HT, hypertension; DL, dyslipidemia; CHF, congestive heart failure. 
Table 2 Risk factors of CQ retinopathy

\begin{tabular}{|c|c|c|c|c|}
\hline Risk factors & $\begin{array}{l}\text { Retinopathy }(\mathrm{N}=14) \\
\text { median (min-max) }\end{array}$ & $\begin{array}{l}\text { No retinopathy }(\mathrm{N}=159) \\
\text { median (min-max) }\end{array}$ & Hazard ratio & $P$-value \\
\hline Age (years) & $53(27-65)$ & $44(15-78)$ & $1.06(1.00-1.12)$ & 0.04 \\
\hline Age $>60$ years $^{a}$ & 3 & 16 & $2.98(0.82-10.73)$ & 0.10 \\
\hline Gender (male) ${ }^{\mathrm{a}}$ & 6 & 37 & $1.68(0.55-5.14)$ & 0.36 \\
\hline Real weight (kg) & $57(48-98)$ & $53(36-80)$ & $1.05(1.00-1.10)$ & 0.04 \\
\hline Hypertension ${ }^{\mathrm{a}}$ & I & 6 & $1.07(0.14-8.24)$ & 0.95 \\
\hline Diabetes mellitus $^{\mathrm{a}}$ & 2 & 8 & $1.83(0.24-13.89)$ & 0.56 \\
\hline Dyslipidemia $^{a}$ & I & 3 & $2.22(0.29-17.45)$ & 0.44 \\
\hline Duration (days) & $724(139-2,033)$ & $397(17-3,307)$ & - & 0.60 \\
\hline Duration $>5$ years & I & 25 & - & 0.39 \\
\hline Cumulative dose (g) & $101.3(14.3-325.1)$ & $91.5(6-1,111.1)$ & $0.99(0.98-1.00)$ & 0.03 \\
\hline Cumulative dose $>460 \mathrm{~g}$ & 0 & 6 & - & - \\
\hline Daily dose (mg/d) & $250(46.8-250)$ & $234(54.3-500)$ & $1.00(0.99-1.01)$ & 0.50 \\
\hline Daily dose $>250 \mathrm{mg} / \mathrm{d}$ & 0 & 3 & - & - \\
\hline Daily dose/RW (mg/kg/d) & $4.2(0.8-18.5)$ & $4.2(0.83-25.64)$ & $1.03(0.92-1.16)$ & 0.58 \\
\hline Daily dose $/ \mathrm{RW}>2.3 \mathrm{mg} / \mathrm{kg} / \mathrm{d}$ & 9 & 126 & $\mathrm{I} .27(0.42-3.8 \mathrm{I})$ & 0.67 \\
\hline
\end{tabular}

Note: aData are shown in numbers.

Abbreviations: $\mathrm{CQ}$, chloroquine; $\mathrm{RW}$, real weight; min, minimum; max, maximum.

In the HCQ group, 2 of 61 patients developed retinopathy; therefore, the incidence of HCQ retinopathy was $3.28 \%$ over the 10 years of the study. Both patients were also categorized as having "possible" toxicity as evidenced by indirect ophthalmoscopic examination, HVF test, and OCT findings. The specific details of these patients are shown in Table 3. The risk factors are shown in Table 4. Other underlying diseases such as thyroid disease, bulimia nervosa, anemia, hepatitis, rheumatic heart disease, and ischemic stroke were also noted in patients in the retinopathy-negative group. In contrast to $\mathrm{CQ}$, no statistically significant hazard ratios of any items studied in the HCQ group were found. The incidence of CQ and HCQ retinopathy versus duration of medication use were analyzed via Kaplan-Meier survival analysis and are illustrated in Figures 1 and 2. It is noted that CQ retinopathy can occur as early as 4 months after drug use. Moreover, both CQ and HCQ retinopathy can develop within the first 3 years.

\section{Discussion}

According to results of this study, the incidence of CQ retinopathy was $8.09 \%$ over 10 years. Back in the 19 th century, CQ retinopathy was diagnosed by the appearance of bull's eye maculopathy in patients taking CQ. This presentation indicated disease in the full-blown stage. As a result, the studies conducted on the disease yielded quite a very low prevalence of disease, 1 in $270 .{ }^{12}$ Currently, physicians tend to detect CQ retinopathy at an earlier stage on the basis of the revised AAO recommendations; therefore, most of recent studies showed higher prevalence rates ranging from $7.3 \%$ to $26.6 \% .^{9-12}$ The incidence from this study could not be compared directly with previous studies that reported the prevalence. According to the report of life expectancy in rheumatologic patients by Mok et al ${ }^{13}$ and understanding that the normal Thai population has an average life expectancy of 74.72 years, ${ }^{14}$ the prevalence of retinopathy in this study can be calculated from the incidence as being $14.9 \%$, which was in agreement with the previous studies. ${ }^{9-12}$

The revised CQ and HCQ retinopathy screening recommendations of AAO stated that high-risk patients were those who used CQ longer than 5 years, or those who had a cumulative dose $>460 \mathrm{~g}$ or a daily dose $>250 \mathrm{mg} / \mathrm{d}$ or $2.3 \mathrm{mg} / \mathrm{kg}$ real weight $/ \mathrm{d}$, or those who were elderly or had concurrent liver or renal dysfunction. ${ }^{3,4}$ This current study seemed to agree with the recommendations that the

Table 3 Specific details of the patients with HCQ retinopathy

\begin{tabular}{|c|c|c|c|c|c|c|c|c|c|c|}
\hline Number & $\begin{array}{l}\text { Age } \\
\text { (years) }\end{array}$ & Gender & $\begin{array}{l}\text { Weight } \\
\text { (kg) }\end{array}$ & $\begin{array}{l}\text { Underlying } \\
\text { diseases }\end{array}$ & $\begin{array}{l}\text { Rheumato- } \\
\text { logic diseases }\end{array}$ & $\begin{array}{l}\text { Duration } \\
\text { (days) }\end{array}$ & $\begin{array}{l}\text { Cumulative } \\
\text { dose (g) }\end{array}$ & $\begin{array}{l}\text { Cumulative } \\
\text { dose } / \mathrm{kg}(\mathrm{g} / \mathrm{kg})\end{array}$ & $\begin{array}{l}\text { Daily dose/d } \\
\text { (mg/d) }\end{array}$ & $\begin{array}{l}\text { Daily dose/kg/d } \\
(\mathrm{mg} / \mathrm{kg} / \mathrm{d})\end{array}$ \\
\hline 1 & 36 & $\mathrm{~F}$ & 45 & RHD & SLE & 828 & 130.2 & 2.89 & 157.25 & 3.49 \\
\hline 2 & 39 & $\mathrm{~F}$ & 68 & AlHA & SLE & 660 & 80 & 1.18 & $|2| .2 \mid$ & 1.78 \\
\hline
\end{tabular}

Abbreviations: HCQ, hydroxychloroquine; F, female; SLE, systemic lupus erythematosus; RHD, rheumatic heart disease; AlHA, autoimmune hemolytic anemia. 
Table 4 Risk factors of HCQ retinopathy

\begin{tabular}{|c|c|c|c|c|}
\hline Risk factors & $\begin{array}{l}\text { Retinopathy }(\mathbf{N}=2) \\
\text { median (min-max) }\end{array}$ & $\begin{array}{l}\text { No retinopathy }(\mathbf{N}=\mathbf{5 9}) \\
\text { median (min-max) }\end{array}$ & Hazard ratio & $P$-value \\
\hline Age (years) & $37.5(36-39)$ & $43(18-72)$ & $0.99(0.89-1.09)$ & 0.80 \\
\hline Age $>60$ years & 0 & 6 & - & - \\
\hline Gender (male) $^{\mathrm{a}}$ & 0 & 8 & - & - \\
\hline Real weight (kg) & $56.5(45-68)$ & $54(33-73)$ & $\mathrm{I} .04(0.90-\mathrm{I} .20)$ & 0.62 \\
\hline Hypertension ${ }^{a}$ & 0 & 2 & - & - \\
\hline Diabetes mellitus $^{\mathrm{a}}$ & 0 & 2 & - & - \\
\hline Dyslipidemia $^{a}$ & 0 & I & - & - \\
\hline Duration (days) & 744 (660-828) & $331(18-3,052)$ & $\mathrm{I} .48(0.72-3.07)$ & 0.53 \\
\hline Duration $>5$ years & 0 & I & - & - \\
\hline Cumulative dose (g) & $105.1(80-130)$ & $77.6(8.4-375.6)$ & $1.00(0.98-1.01)$ & 0.62 \\
\hline Cumulative dose $>1,000 \mathrm{~g}$ & 0 & 0 & - & - \\
\hline Daily dose (mg/d) & I 64.7 (I29.4-200) & $200(40.22-500)$ & $1.00(0.98-1.02)$ & 0.86 \\
\hline Daily dose $>400 \mathrm{mg} / \mathrm{d}$ & 0 & I & - & - \\
\hline Daily dose/RW (mg/kg/d) & $3.2(1.9-4.4)$ & $3.8(0.7-9.8)$ & $0.93(0.35-2.53)$ & 0.89 \\
\hline Daily dose $/ \mathrm{RW}>5 \mathrm{mg} / \mathrm{kg} / \mathrm{d}$ & 0 & 6 & - & - \\
\hline
\end{tabular}

Note: ${ }^{a}$ Data are shown in numbers.

Abbreviations: $\mathrm{HCQ}$, hydroxychloroquine; RW, real weight; min, minimum; max, maximum.

elderly are at higher risk than younger patients, but the median age was less than 60 years. Chiowchanwisawakit et al, also demonstrated that the elderly ( $>60$ years) had a significant association with CQ retinopathy. ${ }^{9}$ This was because their studied populations were only RA patients who were basically older than patients with other connective tissue diseases such as SLE or SS. However, Puavilai et al and Leecharoen et al reported no relationship between old age and CQ retinopathy. ${ }^{10,11}$ This might be because they included pediatric patients in their studies.

Table 2 also shows that real body weight was one of the statistically significant risk factors for CQ retinopathy. However, the size of the difference was too small to indicate clinical significance. Regardless of the effect of dose per unit of body weight, no previous studies mentioned the relationship between body weight and occurrence of CQ retinopathy.

This study found no relationship between duration of CQ use and CQ retinopathy, whereas the revised recommendations of AAO concluded the opposite and recommended screening tests starting not earlier than 5 years of CQ use. Moreover, those patients in the CQ retinopathypositive group developed the disease at a median time of 724 days (1.98 years), ranging from 139 to 2,033 days (0.38-5.57 years), and only one of them had used CQ for more than 5 years. Similar results were reported by Chiowchanwisawakit et al, Leecharoen et al, and Puavilai et al. ${ }^{9-11}$ The latter recommended screening tests to be done every 6 months after the baseline test. Surprisingly, the Kaplan-Meier analysis of CQ presented in Figure 1 revealed that CQ retinopathy mostly developed within the first 3 years after the patients started the medication and that no retinopathy was detected after 6 years. These results were in contrast to the AAO recommendations.

Despite the fact that the present study showed a statistically significant relationship between the occurrence of CQ retinopathy and cumulative dose, the results were too small to be clinically significant. In addition, the cumulative dose these patients with CQ retinopathy received, $101.3 \mathrm{~g}$ (ranging from 14.3 to $325.1 \mathrm{~g}$ ), was far less than $460 \mathrm{~g}$ recommendation of the AAO for the high-risk group. The daily dose of CQ retinopathy group in this study was $250 \mathrm{mg} / \mathrm{d}$ (averaged $>4 \mathrm{mg} / \mathrm{kg} / \mathrm{d}$ ). Since the available CQ was manufactured as $250 \mathrm{mg}$ tablets, the rheumatologist had to prescribe CQ at multiplicands of $250 \mathrm{mg}$ doses, and

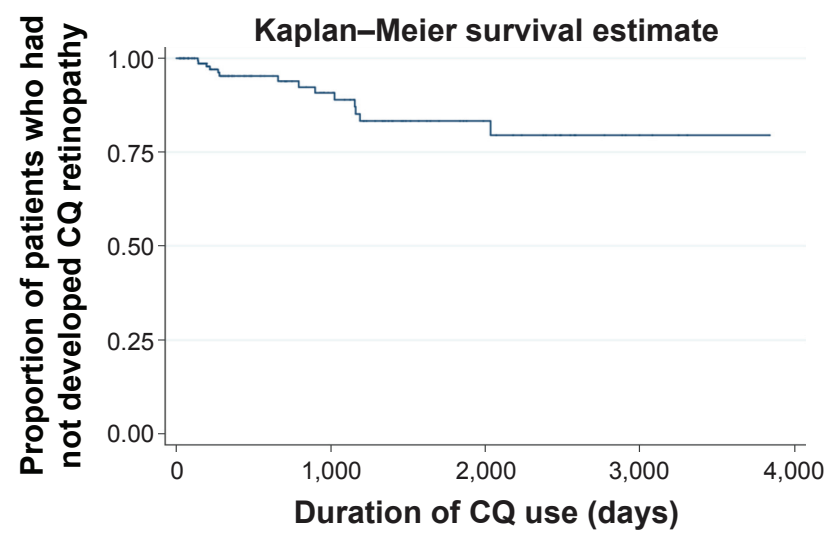

Figure I Kaplan-Meier survival analysis of patients with CQ retinopathy. Note: $Y$-axis represents patients who had not developed retinopathy and $X$-axis represents duration of $C Q$ use.

Abbreviation: $\mathrm{CQ}$, chloroquine. 


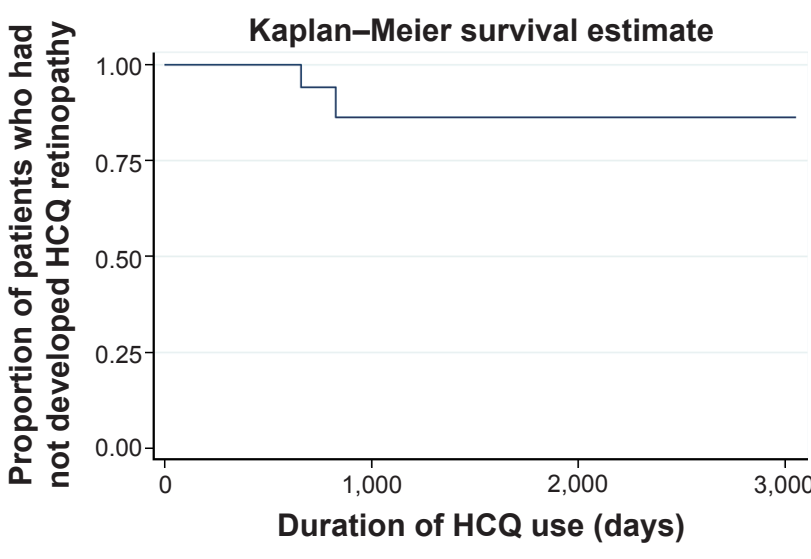

Figure 2 Kaplan-Meier survival analysis of patients with HCQ retinopathy. Note: $Y$-axis represents patients who had not developed retinopathy and $X$-axis represents duration of HCQ use.

Abbreviation: $\mathrm{HCQ}$, hydroxychloroquine.

therefore the dose was usually $250 \mathrm{mg} / \mathrm{d}$. This is the reason no significant differences of daily doses in retinopathy in the retinopathy-negative group were found. Unfortunately, with a daily dose of $250 \mathrm{mg} / \mathrm{d}$, most of the patients received CQ doses exceeding $2.3 \mathrm{mg} / \mathrm{kg} / \mathrm{d}$, which is the safe dose according to the AAO recommendations. This could be the reason CQ retinopathy in the Thai patients developed earlier and with a less cumulative dose than the previous studies conducted in Caucasian populations. Also, CQ binds to the melanin pigment of the RPE, which, perhaps, leads to toxicity and damage to RPE. Since Thai populations have more melanin pigment than Caucasians, CQ might accumulate more in the RPE than it would in the Caucasian eyes. There is currently no conclusive mechanism known for CQ retinopathy. The role of RPE and CQ binding to melanin pigment is still unclear and should be further investigated.

According to the results of the present study, the incidence of HCQ retinopathy was $3.28 \%$ over 10 years, which was consistent with the results of a meta-analysis conducted in 2006, which concluded that the incidence of HCQ retinopathy ranged from $0 \%$ to $4 \% .{ }^{15} \mathrm{~A}$ recent prospective study reported an incidence of only $0.65 \% .{ }^{16}$

None of the risk factors showed statistical significance in the present study, as opposed to the revised AAO recommendations. A large prospective study, however, has shown consistent results with the current study of no significant risk factors. ${ }^{16}$ Aging showed no relation to the HCQ retinopathy in the patients. The participants diagnosed with HCQ retinopathy were 36 and 39 years old (median 37.5 years). As compared to the revised AAO recommendations, retinopathy developed at a younger age. Wolfe and Marmor, ${ }^{16}$ in a recent, large prospective study, showed no relation between aging and HCQ retinopathy.

HCQ retinopathy developed in 2 patients who received HCQ for 660-828 days (1.81-2.27 years), a median of 744 days (2.04 years); not nearly reaching 5 years. It was mainly noted that there was no retinopathy found after 3 years. These 2 patients received the drug cumulatively from 80 to $130 \mathrm{~g}$ (median $105.1 \mathrm{~g}$ ), which was far less than the $1,000 \mathrm{~g}$ of cumulative dose recommended by AAO. It can actually be seen that the there is a possible difference between the duration and daily dose of HCQ retinopathy and the retinopathy-negative patients, but the statistics fail to show the significance because of the small number of participants. Similar to the results of CQ, the patients seemed not to tolerate as high a HCQ dose as the AAO recommendations.

Patients who developed HCQ retinopathy used HCQ at an average dose of 129.4-200 mg/d (median $164.7 \mathrm{mg} / \mathrm{d}$ ). For the same reasons as with the CQ group, the daily dosages of not only patients who were retinopathy positive, but also those who were retinopathy negative tended to be approximately equal to the available dose of the HCQ tablet $-200 \mathrm{mg}$. Nevertheless, unlike the CQ group, the daily dose per real body weight of the patients who were HCQ retinopathy positive was only $1.9-4.4 \mathrm{mg} / \mathrm{kg} / \mathrm{d}$ (median: $3.2 \mathrm{mg} / \mathrm{kg} / \mathrm{d}$ ), which was less than the daily dose recommended by the AAO. In this case, the lower body weight would not be a reasonable explanation for the patients developing retinopathy with less treatment duration and less cumulative dosages compared to Caucasians. The theory of correlation between HCQ binding to melanin pigment in RPE and its toxicity could be a possible explanation; hence, further studies on pathophysiology of the disease should be done in the future in order to understand these findings.

\section{Strength and limitations}

One of the important aims of this study was to assess incidence of and risk factors for CQ and HCQ in Thai people. Surprisingly, many results that diverged from the AAO recommendations were found, highlighting the risk factors. These results could lead to further investigation and renewed guidelines for Asian people in the future. An obvious limitation of the study was that we used possible toxicity for diagnosis of CQ and HCQ retinopathy. These early findings may be nonspecific and misinterpreted. Since bull's-eye retinopathy in patients with definite toxicity is a late irreversible finding, we had to report early toxicity and suggest all patients with possible toxicity to stop the medication before they reached the full-blown disease state. However, we 
improved the accuracy of diagnosis by using a combination of 3 diagnostic procedures and demonstrated both functional (HVF) and structural (OCT) changes. Another limitation was that this study was a retrospective study; also, the number of patients was too small in the HCQ group. It is recommended that further prospective studies on the same issue with larger sample sizes be pursued.

\section{Conclusion}

The incidence of CQ retinopathy was $8.09 \%$ over 10 years. There was a statistically significant relationship between age, real body weight, and cumulative dose in patients with retinopathy. It was found that the retinopathy could develop before 5 years and with a lower cumulative dose than $460 \mathrm{~g}$. The daily dose exceeding $2.3 \mathrm{mg} / \mathrm{kg} / \mathrm{d}$ could be the reason.

The incidence of HCQ retinopathy was $3.24 \%$ over 10 years. The study found no statistically significant relation between age, real body weight, duration of HCQ use, cumulative dose, and daily dose. A lack of sufficient patients in the study may have failed to prove the significance of risk factors.

Since CQ and HCQ are essential drugs to control the effects of connective tissue diseases and the patients sometime need higher doses to control the diseases, it is suggested that patients taking long-term CQ or HCQ should undergo one baseline ophthalmologic screening examination at the first visit and annual screening thereafter. Moreover, the routine $250 \mathrm{mg} \mathrm{CQ}$ and $200 \mathrm{mg}$ HCQ tablets should be used cautiously, or divided, especially in patients with low body weight.

\section{Acknowledgments}

The authors thank Dr Kaewjai Thepsuthammarat, Clinical Epidemiology Unit, Faculty of Medicine, Khon Kaen University for statistical analysis and Professor James A Will, University of Wisconsin for assistance with the English-language presentation of the manuscript. This study was supported by invitation research grant (I 57215) from the Faculty of Medicine, Khon Kaen University.

Clinical Ophthalmology

\section{Publish your work in this journal}

Clinical Ophthalmology is an international, peer-reviewed journal covering all subspecialties within ophthalmology. Key topics include: Optometry; Visual science; Pharmacology and drug therapy in eye diseases; Basic Sciences; Primary and Secondary eye care; Patient Safety and Quality of Care Improvements. This journal is indexed on

\section{Disclosure}

The authors report no conflicts of interest in this work.

\section{References}

1. Browning DJ. Pharmacology of chloroquine and hydroxychloroquine. In: Browning DJ, editor. Hydroxychloroquine and Chloroquine Retinopathy. New York, NY: Springer Science+Business Media; 2014: 35-63.

2. American Academy of Ophthalmology. Basic Science and Clinical Course 2013-2014 Retina and Vitreous. San Francisco, CA: FSC; 2013:266-267.

3. Marmor MF, Kellner U, Lai TY, Lyons JS, Mieler WF; American Academy of Ophthalmology. Revised recommendations on screening for chloroquine and hydroxychloroquine retinopathy. Ophthalmology. 2011;118(2):415-422.

4. Marmor MF, Kellner U, Lai TY, Melles RB, Mieler WF; American Academy of Ophthalmology. Recommendations on screening for chloroquine and hydroxychloroquine retinopathy (2016 revision). Ophthalmology. 2016;123:1386-1394.

5. Elman A, Gullberg R, Nilsson E, et al. Chloroquine retinopathy in patients with rheumatoid arthritis. Scand J Rheumatol. 1976;5:161-166.

6. Easterbrook M. Long term case of antimalarial toxicity after cessation of treatment. Can J Ophthalmol. 1992;27:237-239.

7. Levy GD, Munz SJ, Paschal J, et al. Incidence of hydroxychloroquine retinopathy in a large multicenter outpatient practice. Arthritis Rheum. 1997;40:1482-1486

8. Wolfe F, Marmor MF. Rates and predictors of hydroxychloroquine retinal toxicity in patients with rheumatoid arthritis and systemic lupus erythematosus. Arthritis Care Res (Hoboken). 2010;62:775-784.

9. Chiowchanwisawakit P, Nilganuwong S, Srinonprasert V, et al. Prevalence and risk factors for chloroquine maculopathy and role of plasma chloroquine and desethylchloroquine concentrations in predicting chloroquine maculopathy. Int J Rheum Dis. 2013;16(1):47-55.

10. Puavilai S, Kunavisarut S, Vatanasuk M, et al. Ocular toxicity of chloroquine among Thai patients. Int J Dermatol. 1999;38(12):934-937.

11. Leecharoen S, Wangkaew S, Louthrenoo W. Ocular side effects of chloroquine in patients with rheumatoid arthritis, systemic lupus erythematosus and scleroderma. J Med Assoc Thai. 2007;90(1):52-58.

12. Elman A, Gullberg R, Nilsson E, Rendahl I, Wachtmeister L. Chloroquine retinopathy in patients with rheumatoid arthritis. Scand J Rheumatol. 1976;5(3):161-166.

13. Mok CC, Kwok CL, Ho LY, Chan PT, Yip SF. Life expectancy, standardized mortality ratios, and cause of death in six rheumatic disease in Hong Kong, China. Arthritis Rheum. 2011;63(5):1182-1189.

14. The World: Life expectancy 2016 - [cited 2016 Mar 10]. Available from: http://www.geoba.se/

15. Yam JC, Kwok AK. Ocular toxicity of hydroxychloroquine. Hong Kong Med J. 2006;12(4):294-304.

16. Wolfe F, Marmor MF. Rates and predictors of hydroxychloroquine retinal toxicity in patients with rheumatoid arthritis and systemic lupus erythematosus. Arthritis Care Res (Hoboken). 2010;62(6):775-784.

PubMed Central and CAS, and is the official journal of The Society of Clinical Ophthalmology (SCO). The manuscript management system is completely online and includes a very quick and fair peer-review system, which is all easy to use. Visit http://www.dovepress.com/ testimonials.php to read real quotes from published authors. 